\title{
Bilateral acromial stress fractures in a patient with a massive rotator cuff tear
}

\author{
Du-Han Kim, Sang-Soo Na, Chung-Sin Baek, Chul-Hyun Cho \\ Department of Orthopedic Surgery, Dongsan Medical Center, Keimyung University School of Medicine, Daegu, Korea
}

\begin{abstract}
Stress fractures of the acromion and scapular spine are well-known complications following reverse total shoulder arthroplasty. However, these fractures in patients with massive rotator cuff tear or cuff tear arthropathy are extremely rare, and the pathogenesis, clinical features, diagnosis, and treatment of these fractures are poorly understood. We report a case of bilateral stress fracture of the posterior angle of the acromion in a patient with massive rotator cuff tear and discuss the pathogenesis, clinical manifestation, and treatment with a review of the literature.
\end{abstract}

Keywords: Scapula; Acromion; Fracture; Rotator cuff tear

Stress fractures of the acromion and scapular spine are well-known complications following reverse total shoulder arthroplasty (RTSA) [1]. However, stress fractures of the acromion and scapular spine in patients without any previous surgeries are extremely rare and have only been described in case reports in which the possible causes included repetitive subcritical trauma in healthy populations [2-4], massive rotator cuff tear (MRCT) or cuff tear arthropathy (CTA) [5-9], and RTSA [1]. Especially, stress fractures of the acromion and scapular spine in patients with MRCT or CTA are poorly understood for their pathogenesis, clinical features, diagnosis, and treatment because of their rarity. We report a case of bilateral stress fracture of the posterior acromion in a patient with MRCT and discuss the pathogenesis, clinical manifestation, and treatment with a review of the literature.

\section{CASE REPORT}

An 80-year-old woman visited Keimyung University Dongsan Medical Center with severe pain and limited motion of the right shoulder for 2 weeks. There was no history of acute trauma. She was an orchard farmer with long-standing pain in both shoulders for 10 years. One year ago, she was diagnosed with irreparable MRCT on her right shoulder, and RTSA was recommended by a physician at the local clinic if her pain and disability worsened.

Physical examination of the right shoulder revealed overall tenderness on the superior and posterior area without swelling or redness. The active range of motion (ROM) was not able to be assessed due to severe pain. The $\mathrm{t}$-score of bone mineral density was -4.9. Plain radiographs and computed tomography (CT) on the right shoulder revealed a slightly displaced fracture of the posterior angle of the acromion and superior migration of the humeral head

Received: February 23, $2020 \quad$ Revised: March 14, $2020 \quad$ Accepted: March 17, 2020

Correspondence to: Chul-Hyun Cho

Department of Orthopedic Surgery, Dongsan Medical Center, Keimyung University School of Medicine, 56 Dalseong-ro, Jung-gu, Daegu 41931, Korea Tel: +82-53-258-4772, Fax: +82-53-258-4773, E-mail: oscho5362@dsmc.or.kr, ORCID: https://orcid.org/0000-0003-0252-8741

Financial support: None.

Conflict of interest: None.

Copyright@ 2020 Korean Shoulder and Elbow Society. All Rights Reserved.

This is an Open Access article distributed under the terms of the Creative Commons Attribution Non-Commercial License (http://creativecommons.org/licenses/by-nc/4.0/) which permits unrestricted non-commercial use, distribution, and reproduction in any medium, provided the original work is properly cited. 
(Fig. 1). Magnetic resonance imaging revealed chronic MRCT involving the supraspinatus, infraspinatus, and subscapularis (Fig. 2). The torn supraspinatus and infraspinatus tendons were retracted at the level of the glenoid with moderate muscle atrophy and fatty infiltration.

Because the patient also had long-standing symptoms in the left shoulder, plain radiographs of the left shoulder were obtained and revealed nonunion of the posterior part of the acromion and superior migration of humeral head (Fig. 3). On physical examination of the left shoulder, there was no specific tenderness on the acromion and active ROM was $140^{\circ}$ of forward flexion, $130^{\circ}$ of abduction, $60^{\circ}$ of external rotation at the side, and internal rotation of the third lumbar vertebra level. She vaguely remembered a history of sudden onset pain and limited motion in the left shoulder several
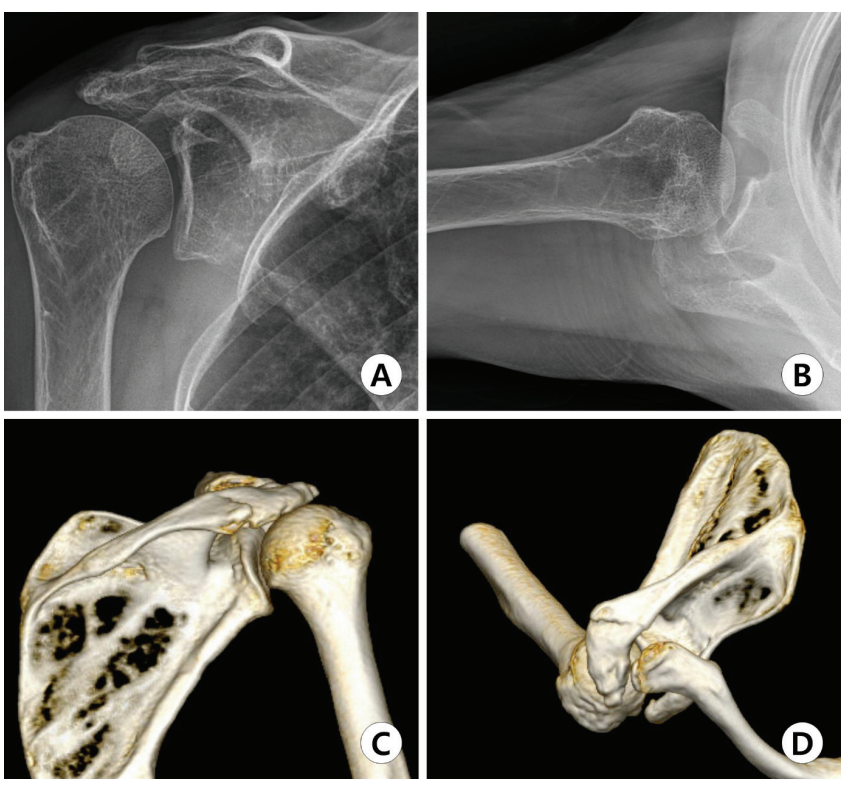

Fig. 1. Plain radiographs (A, B) and three-dimensional computed tomography $(\mathrm{C}, \mathrm{D})$ scan showed a slightly displaced acromial fracture through the posterior to the acromioclavicular joint and superior migration of the humeral head.
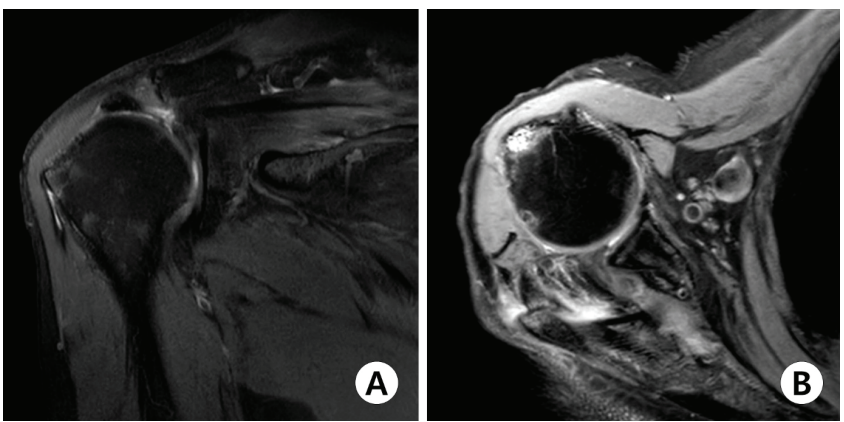

Fig. 2. (A, B) Magnetic resonance imaging demonstrated chronic massive rotator cuff tear involving the supraspinatus, infraspinatus, and subscapularis. years ago. The symptoms improved by conservative treatment from the local clinic. However, she didn't remember the exact diagnosis of the left shoulder at that time.

Despite conservative treatment including immobilization and medication for 2 weeks after initial presentation, the patient complained of unbearable right shoulder pain, and ROM had not improved. Therefore, the patient opted for open reduction and internal fixation (ORIF) and provided consent. After induction of general anesthesia, the patient was placed in the $60^{\circ}$ beach chair position. An incision was made along the scapular spine towards the lateral edge of the acromion. After soft tissue dissection, the trapezius and deltoid fascia were opened towards the spine, and the fracture site was exposed. After the fracture was reduced using reduction forceps, two cannulated screws were fixed in a direction perpendicular to the fracture line. Then, a lateral clavicle anatomical plate (Acumed, Hillsboro, OR, USA) was bent along the acromial bony contour and fixed.

After surgery, the patient experienced immediate pain relief and started passive ROM exercise 2 weeks later. Two years after surgery, plain radiographs revealed complete healing of the fracture (Fig. 4). The active ROM was $130^{\circ}$ of forward flexion, $120^{\circ}$ of abduction, $50^{\circ}$ of external rotation at the side, and internal rotation of the second lumbar vertebra level. Her visual analogue scale for pain, American Shoulder and Elbow Surgeons score, and Subjec-
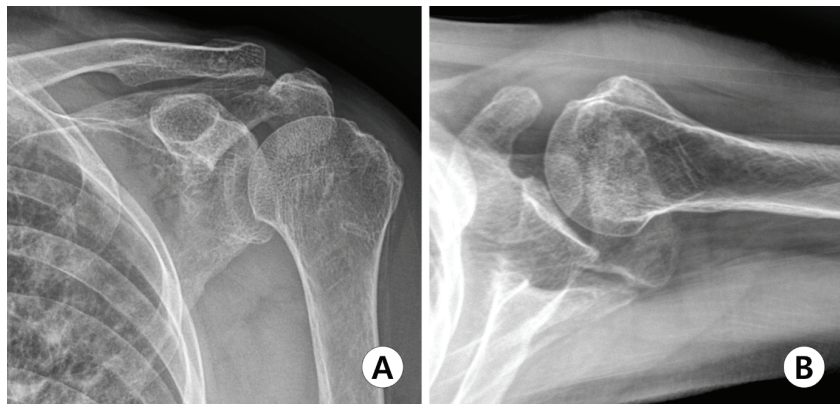

Fig. 3. (A, B) Plain radiographs revealed nonunion of the posterior part of the acromion and superior migration of the humeral head.
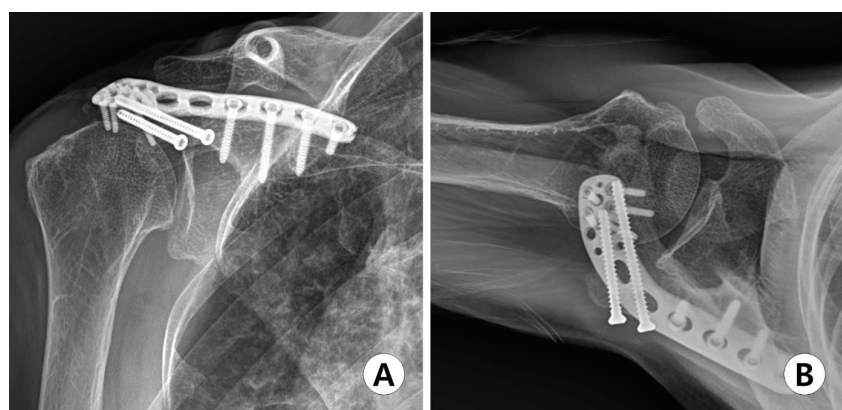

Fig. 4. Plain radiographs (A, B) 2 years after surgery showed complete union of the fracture. 
tive Shoulder Value were 1, 82, and 70\%, respectively.

\section{DISCUSSION}

Stress fractures of the acromion and scapular spine in patients with MRCT or CTA are extremely rare and poorly understood. To date, there have been 11 cases reported in five studies of stress fractures of the acromion and scapular spine in patients with CTA (Table 1) [5-9].

Previous studies proposed the mechanism of stress fracture according to fracture location [5,8,9]. Dennis et al. [5] reported acromial stress fractures caused by superior migration of the humeral head in patients with MRCT or CTA. Abnormal pressure from the humeral head on the acromion in patients with CTA leads to acromial thinning and subsequent fracture of the anterior or lateral acromion [8]. Meanwhile, the mechanism for stress fractures of the acromial base or scapular spine in patients with CTA may be different. Shindle et al. [9] reported that scapular spine stress fractures are the result of altered mechanics about the shoulder compensating for the lack of a rotator cuff. They reported two cases of scapular spine stress fracture due to an indirect mechanism of a bending moment created by the trapezius and deltoid [9]. In the present study, our case had bilateral stress fractures of the posterior angle of the acromion in patient with MRCT, not CTA. Although superi- or migration of both humeral heads was evident, the acromiohumeral interval was preserved to more than $5 \mathrm{~mm}$. Therefore, the pathomechanism in our case may be consistent with that proposed by Shindle et al. [9].

Patients with CTA who experienced stress fractures of the acromion or scapular fractures had sudden onset shoulder pain without a history of trauma, although the pain occurred insidiously as well [5]. If these fractures are suspected from history taking and physical examination, plain radiographs (especially, the axillary lateral view) and CT are useful to confirm the diagnosis. It is important that plain radiographs of the unaffected shoulder be taken, because these fractures can be confused with os acromiale [5]. Stress fracture of the acromion or scapular spine should be considered in the differential diagnosis when patients with MRCT or CTA complain of sudden onset severe shoulder pain and limited motion without a history of trauma.

Previous studies reported that most acromial stress fractures were minimally displaced fractures and healed with conservative treatment, such as immobilization for a few weeks followed by gradual motion [3-5]. Groot et al. [6] reported two cases in patients with CTA and oral steroid therapy who had a scapular spine stress fracture managed by conservative treatment. Although good clinical outcomes were not obtained in another report, conservative treatment seemed a reasonable alternative considering the risk

Table 1. A review of literature

\begin{tabular}{|c|c|c|c|c|c|c|}
\hline Study & No. of fractures & Age (yr) & Sex & Location of factures & Treatment & Outcome \\
\hline \multirow[t]{4}{*}{ Dennis et al. [5] } & 4 & 65 & $\mathrm{~F}$ & Anterior acromion & $\mathrm{CT}$ & Reduced pain \\
\hline & & 65 & $\mathrm{~F}$ & Anterior acromion & CT failed $\rightarrow$ fragment excision & Slight pain c sustained LOM \\
\hline & & 64 & $\mathrm{~F}$ & Anterior acromion & $\mathrm{CT}$ failed $\rightarrow$ fragment excision $+\mathrm{RCR}$ & Satisfactory pain relief; FF, $60^{\circ}$ \\
\hline & & 77 & $\mathrm{~F}$ & Anterior acromion & Fragment excision \& RCR \& TSA & Mild pain; FF, $70^{\circ}$ \\
\hline Roy et al. [8] & 1 & 82 & $\mathrm{~F}$ & Acromial base & $\mathrm{CT}$ & No pain at 6 months \\
\hline \multirow[t]{2}{*}{ Shindle et al. [9] } & 2 & 80 & $\mathrm{~F}$ & Scapular spine & CT failed $\rightarrow$ ORIF & Finally union, no pain \\
\hline & & 78 & $\mathrm{~F}$ & Scapular spine & CT failed $\rightarrow$ RTSA & $\begin{array}{l}\text { MRSA infection, death by } \\
\text { COPD }\end{array}$ \\
\hline \multirow[t]{2}{*}{ Groot et al. [6] } & 2 & 72 & $\mathrm{~F}$ & Scapular spine & $\mathrm{CT}$ & $\begin{array}{l}\text { Stiff shoulder; tolerable pain } \\
\text { controlled by analgesics }\end{array}$ \\
\hline & & 86 & $\mathrm{~F}$ & Scapular spine & $\mathrm{CT}$ & $\begin{array}{l}\text { No pain but acceptable func- } \\
\text { tional disability; ABD, } 60^{\circ} \text {; } \\
\text { ER, } 0^{\circ}\end{array}$ \\
\hline \multirow[t]{2}{*}{ Karthik et al. [7] } & 2 & 61 & M & Scapular spine & CT & $\begin{array}{l}\text { Good clinical \& radiographic } \\
\text { outcomes }\end{array}$ \\
\hline & & 61 & M & Scapular spine & CT failed $\rightarrow$ ORIF & $\begin{array}{l}\text { Good clinical \& radiographic } \\
\text { outcomes }\end{array}$ \\
\hline \multirow[t]{2}{*}{ This study } & 2 & 80 & $\mathrm{~F}$ & Posterior acromion & CT failed $\rightarrow$ ORIF & VAS, 1 ; ASES, 82 ; SSV, 70\% \\
\hline & & 80 & $\mathrm{~F}$ & Posterior acromion & CT & VAS, 1 ; ASES, 85 ; SSV, 80\% \\
\hline
\end{tabular}

CT: conservative treatment, LOM: limitation of motion, RCR: rotator cuff repair, FF: forward flexion, TSA: total shoulder arthroplasty, ORIF: open reduction and internal fixation, RTSA: reverse total shoulder arthroplasty, MRSA: methicillin-resistance Staphylococcus aureus, COPD: chronic obstructive pulmonary disease, ABD: abduction, ER: external rotation, VAS: visual analog scale, ASES: American Shoulder and Elbow Surgeons, SSV: subjective shoulder value. 
of operative treatment in elderly patients [6]. On the other hand, several studies reported that acromial stress fractures in patients with CTA may need surgical treatment [5,7-9]. Karthik et al. [7] reported that fracture healing either by conservative or operative treatment is associated with a good functional outcome. Dennis et al. [5] reported four cases describing stress fracture of the anterior acromion associated with CTA. One patient had conservative treatment. Three cases had operative treatment, including two with fragment excision and one with total shoulder arthroplasty and fragment excision. They described the fracture site bathed in synovial fluid, which may make union less likely due to the associated rotator cuff tear [5]. They recommended surgical excision of the fragment rather than internal fixation, as the healing potential is thought to be poor. In previously reported cases, two patients with failed conservative treatment for scapular spine stress fracture underwent ORIF and experienced good clinical outcomes with fracture healing after surgery [7,9]. Considering the previously reported cases and our cases, we recommend initial conservative treatment in patients with stress fracture of the acromion or scapular spine. If conservative treatment fails, we recommend ORIF rather than fragment excision and rotator cuff repair, or RTSA may be not necessary.

\section{ORCID}

$\begin{array}{ll}\text { Du-Han Kim } & \text { https://orcid.org/0000-0002-6636-9340 } \\ \text { Sang-Soo Na } & \text { https://orcid.org/0000-0001-6086-2815 } \\ \text { Chung-Sin Baek } & \text { https://orcid.org/0000-0002-4184-2568 } \\ \text { Chul-Hyun Cho } & \text { https://orcid.org/0000-0003-0252-8741 }\end{array}$

\section{REFERENCES}

1. Mayne IP, Bell SN, Wright W, Coghlan JA. Acromial and scapular spine fractures after reverse total shoulder arthroplasty. Shoulder Elbow 2016;8:90-100.

2. Malavolta EA, Assunção JH, Sunada EE, Gracitelli ME, Ferreira Neto AA. A stress fracture of the base of the acromion: a case report. BMC Musculoskelet Disord 2014;15:302.

3. Taneja AK, Negromonte FP, Skaf A. Stress injury of the acromion: case report and literature review. Eur J Orthop Surg Traumatol 2013;23 Suppl 2:S189-92.

4. Ward WG, Bergfeld JA, Carson WG Jr. Stress fracture of the base of the acromial process. Am J Sports Med 1994;22:146-7.

5. Dennis DA, Ferlic DC, Clayton ML. Acromial stress fractures associated with cuff-tear arthropathy: a report of three cases. J Bone Joint Surg Am 1986;68:937-40.

6. Groot D, Giesberts AM, van Mourik JB. Spontaneous scapular spine fracture related to rotator cuff pathology: a report of two cases. Strategies Trauma Limb Reconstr 2012;7:105-7.

7. Karthik K, Lau J, Sinha J, Tavakkolizadeh A. Scapular spine stress fractures: to fix or not to fix, our experience in a patient with bilateral fractures and review of the literature. Int J Shoulder Surg 2014;8:90-3.

8. Roy N, Smith MG, Jacobs LG. Stress fracture of base of the acromion. Ann Rheum Dis 2002;61:944-5.

9. Shindle MK, Wanich T, Pearle AD, Warren RF. Atraumatic scapular fractures in the setting of chronic rotator cuff tear arthropathy: a report of two cases. J Shoulder Elbow Surg 2008;17:e4-8. 